\title{
Complications of Total Knee Arthroplasty
}

\section{Standardized List and Definitions of The Knee Society}

\author{
William L. Healy MD, Craig J. Della Valle MD, Richard Iorio MD, \\ Keith R. Berend MD, Fred D. Cushner MD, David F. Dalury MD, \\ Jess H. Lonner MD
}

Published online: 19 July 2012

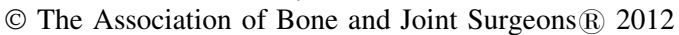

\begin{abstract}
Background Despite the importance of complications in evaluating patient outcomes after TKA, definitions of TKA complications are not standardized. Different investigators report different complications with different definitions when reporting outcomes of TKA.
\end{abstract}

Questions/purposes We developed a standardized list and definitions of complications and adverse events associated with TKA.

Methods In 2009, The Knee Society appointed a TKA Complications Workgroup that surveyed the orthopaedic literature and proposed a list of TKA complications and adverse events with definitions. An expert opinion survey

(JHL) certifies that he, or a member of his immediate family, has received or may receive payments or benefits, during the study period, an amount in excess of $\$ 100,000$ from Zimmer Inc (Warsaw, IN, USA), MAKO Surgical Corp (Ft Lauderdale, FL, USA), Healthpoint Capital (New York, NY, USA), and CD Diagnostics.

All ICMJE Conflict of Interest Forms for authors and Clinical Orthopaedics and Related Research editors and board members are on file with the publication and can be viewed on request. This work was primarily performed at Lahey Clinic, Burlington, MA, USA.

W. L. Healy ( $₫)$, R. Iorio

Department of Orthopaedic Surgery, Lahey Clinic Medical

Center, 41 Mall Road, Burlington, MA 01805, USA

e-mail: william.1.healy@lahey.org

C. J. Della Valle

Rush University Medical Center, Chicago, IL, USA

K. R. Berend

Joint Implant Surgeons, Inc, New Albany, OH, USA

F. D. Cushner

Insall Scott Kelly Institute, New York, NY, USA

D. F. Dalury

Towson Orthopaedic Associates, Towson, MD, USA

J. H. Lonner

Rothman Institute, Thomas Jefferson University, Philadelphia, PA, USA 
of members of The Knee Society was used to test the applicability and reasonableness of the proposed TKA complications. For each complication, members of The Knee Society were asked "Do you agree with the inclusion of this complication as among the minimum necessary for reporting outcomes of knee arthroplasty?" and "Do you agree with this definition?"

Results One hundred two clinical members (100\%) of The Knee Society responded to the survey. All proposed complications and definitions were endorsed by the members, and 678 suggestions were incorporated into the final work product. The 22 TKA complications and adverse events include bleeding, wound complication, thromboembolic disease, neural deficit, vascular injury, medial collateral ligament injury, instability, malalignment, stiffness, deep joint infection, fracture, extensor mechanism disruption, patellofemoral dislocation, tibiofemoral dislocation, bearing surface wear, osteolysis, implant loosening, implant fracture/tibial insert dissociation, reoperation, revision, readmission, and death.

Conclusions We identified 22 complications and adverse events that we believe are important for reporting outcomes of TKA. Acceptance and utilization of these standardized TKA complications may improve evaluation and reporting of TKA outcomes.

\section{Introduction}

Reporting of complications is important for assessing outcomes of surgical procedures and accurately measuring healthcare quality. Stedman's Medical Dictionary defines a medical complication as "a morbid process or event occurring during a disease which is not an essential part of the disease, although it may result from it or from independent causes" [11]. Complications can occur after surgical operations for many diverse reasons, including an evolving disease process, a surgical error, a medical error, a nursing error, patient noncompliance, and events without error beyond physician or patient control such as falls or trauma. Adverse events after an operation or procedure are conditions that may compromise the process of care or the outcome of care, but not all adverse events are complications. Complications and adverse events can be expected with surgical procedures at a small but finite incidence, despite the exercise of reasonable and safe care.

Medicine has a strong tradition of learning from complications and adverse events. Introspective mortality and morbidity conferences are peer review exercises where complications of care and adverse events are presented to peers for discussion and education. The goal of these conferences is to identify etiologies of complications and adverse events, improve quality of patient care, and enhance patient safety.

Quality measurement in healthcare and public reporting of patient outcomes are becoming more important and will be more prevalent during the next decade. Valid public reporting requires standardization of data collection and data sets, consistent methods of data reporting, and utilization of validated standardized evaluation instruments. Reporting of complications is an essential component of patient outcome, but complication reporting is not standardized, and complications are not always included in reports of patient outcome. Goldhahn et al. [9] performed a systematic review of randomized controlled clinical trials in the orthopaedic literature and determined there was no consistent standard universal reporting of complications in orthopaedics.

TKA is one of the most clinically successful and costeffective medical procedures developed during the last $1 / 2$ century $[5,15,19,23]$. The utilization of TKA is increasing, considerable growth of TKA is projected during the next decade [7, 14, 17, 18, 28], and increased utilization has made TKA one of the highest cost centers for the Centers of Medicare and Medicaid Services [10, 14, 17].

As the utilization and cost of TKA increase, many stakeholders are interested in measuring the quality of TKA outcomes and controlling the cost of TKA. Pain, function, patient satisfaction, patient well-being, and radiographic results have been used in a number of clinical scoring systems to evaluate TKA including The Knee Society Score [12], Hospital for Special Surgery Knee Score [13], Oxford Knee Score [3], WOMAC [1], SF-36 [20], and SF-12 [6, 24]. Furthermore, a revised, updated, and validated Knee Society Knee Score has recently been published [21, 25]. These instruments allow surgeons, investigators, healthcare payers, and government administrators to evaluate the outcome of TKA with validated standardized methods of measurement.

In sharp contrast to the standardized reporting of surgical results and patient outcomes for TKA, reporting of complications and adverse events after TKA is not standardized. Different investigators report different complications with different definitions when evaluating knee arthroplasties [9, 26]. However, reporting complications of surgical procedures may be as important as reporting surgical results and patient outcomes. Complications and adverse events can identify potential problems with patient selection, surgical procedures, clinical pathways, followup care, and joint implants [24]. Standardized reporting of complications for surgical procedures can help clinicians improve patient selection, surgical technique, quality of care, patient safety, and patient outcomes [8, 22]. Furthermore, standardized reporting of complications and adverse events can improve comparative studies of surgical procedures and surgical implants [4, 9, 27]. 
We therefore developed a standardized list of the minimum necessary complications and adverse events for accurate reporting of TKA outcomes and standardized definitions of these complications.

\section{Materials and Methods}

The Knee Society (http://www.kneesociety.org) is an orthopaedic specialty organization based in the United States [16]. The mission of The Knee Society includes advancing knowledge of the knee in health and disease and promoting and maintaining professional standards to provide the best care to patients with arthritic disorders of the knee [16]. The Knee Society is composed of orthopaedic surgeons and researchers who are selected for membership based on "demonstrated interest in the advancement of orthopaedic surgical knowledge of the knee joint in health and/or arthritic disorders of the knee through substantial accomplishments such as special studies, writings, lectures, etc" [16]. Members of The Knee Society are generally acknowledged as experts regarding TKA.

In 2009, The Knee Society established a TKA Complications Workgroup to develop guidelines for reporting complications and adverse events after TKA. The goal of the workgroup was to develop a standardized list of the minimum complications required for accurate reporting of outcomes of TKA. A further goal was to develop standardized definitions for these TKA complications and adverse events. The definitions were intended to be simple, clear, and consistent with ICD-9 codes and the new Knee Society Score $[21,25]$.

During 2009 and 2010, the TKA Complications Workgroup examined the orthopaedic literature on outcomes in TKA via PubMed and surveyed literature on surgical complication reporting. The workgroup then developed a list of minimum necessary TKA complications and a definition for each TKA complication. Conditions that could not be clearly defined as complications or adverse events directly related to the TKA surgery were not included on the list; for example, medical complications (cardiac, pulmonary, renal, etc), anesthetic issues (nausea, arrhythmias, memory loss, etc), poor functional outcome, and pressure sore were not included. ICD-9 codes were provided for each proposed TKA complication and adverse event.

The workgroup used an expert opinion survey of members of The Knee Society to test the applicability and reasonableness of the proposed TKA complications and adverse events. For each complication, members were asked "Do you agree with the inclusion of this complication as among the minimum necessary for reporting outcomes of knee arthroplasty?" and "Do you agree with this definition?" In addition, the members were asked to submit additional complications that the workgroup may have omitted, delete inappropriate complications, and suggest revisions for the proposed definitions of TKA complications. One hundred two clinical members (100\%) of The Knee Society responded to the TKA Complications Survey.

We evaluated the differences of the yes-no questions with chi-square tests. An item (complication or adverse event) was determined acceptable if at least $60 \%$ of the respondents/surgeons responded with an affirmative response ("yes"). Each item was evaluated as to whether an approve/agree response was statistically higher than $60 \%$ using a one-way chi-square test against the specific proportion of $60 \%$ "yes" responses. Approve/agree responses for each item and each category ("agree to include" and "agree with definition") that were statistically higher than $60 \%$ at a $\mathrm{p}$ value $<0.01$ were considered significant.

\section{Results}

All of the proposed TKA complications and adverse events were endorsed by the members of The Knee Society, with each reaching significance (approve inclusion $>60 \%$, $\mathrm{p}<0.01$ ). All of the definitions of TKA complications and adverse events were endorsed by the members of The Knee Society, with each reaching significance (approve definition $>60 \%, p<0.01$ ). Members also provided $678 \mathrm{com}-$ ments and suggestions for improvement.

All responses from members of The Knee Society were evaluated by the TKA Complications Workgroup. The list and the definitions of TKA complications and adverse events were revised based on these responses. The changes suggested by the members, the revised list of TKA complications, and the revised definitions were sent back to the members of The Knee Society for a second review. Finally, the project was presented to the members of The Knee Society at the members' meeting in September 2011. The 22 TKA complications and adverse events and their definitions endorsed by The Knee Society are listed (Table 1).

\section{Discussion}

Complications have been used in the surgical literature as outcome measures and proxies for quality and to compare the efficacy, quality, and safety of surgical treatments and surgical implants. However, the surgical literature does not provide standardized lists of complications or standardized definitions of surgical complications. Nonstandardized and inconsistent methods of reporting complications render the use of complications for quality measurement unreliable [27]. To improve patient safety, quality of orthopaedic care, and evaluation of orthopaedic treatments and 
Table 1. Responses of members of The Knee Society regarding TKA complications and adverse events and their definitions*

\begin{tabular}{|c|c|c|c|c|}
\hline $\begin{array}{l}\text { Complication/Adverse } \\
\text { event }\end{array}$ & $\begin{array}{l}\text { ICD-9 } \\
\text { code }\end{array}$ & $\begin{array}{l}\% \text { agree } \\
\text { with } \\
\text { complication }\end{array}$ & Definition & $\begin{array}{l}\% \text { agree } \\
\text { with } \\
\text { definition }\end{array}$ \\
\hline 1. Bleeding & 998.11 & 99.0 & Postoperative bleeding requiring surgical treatment & 75.8 \\
\hline 2. Wound complication & 998.32 & 99.0 & $\begin{array}{l}\text { Failure of wound healing requiring reoperation or a change in } \\
\text { TKA protocol }\end{array}$ & 77.8 \\
\hline $\begin{array}{l}\text { 3. Thromboembolic } \\
\text { disease }\end{array}$ & 453.40 & 97.0 & $\begin{array}{l}\text { Symptomatic thromboembolic event requiring more intensive, } \\
\text { nonprophylactic anticoagulant or antithrombotic treatment } \\
\text { during the first } 3 \text { months after index TKA }\end{array}$ & 87.9 \\
\hline 4. Neural deficit & 997.09 & 94.9 & $\begin{array}{l}\text { Postoperative neural deficit (sensory or motor) related to the } \\
\text { index TKA }\end{array}$ & 90.9 \\
\hline 5. Vascular injury & 997.20 & 96.0 & $\begin{array}{l}\text { Intraoperative vascular injury requiring surgical repair, bypass } \\
\text { grafting, or stenting (compartment syndrome or amputation } \\
\text { should be reported) }\end{array}$ & 97.0 \\
\hline $\begin{array}{l}\text { 6. Medial collateral } \\
\text { ligament injury }\end{array}$ & 844.10 & 92.9 & $\begin{array}{l}\text { Intraoperative or early postoperative medial collateral ligament } \\
\text { injury requiring repair, reconstruction, a change in prosthetic } \\
\text { constraint, revision surgery, or TKA protocol }\end{array}$ & 93.9 \\
\hline 7. Instability & 996.42 & 92.8 & $\begin{array}{l}\text { Symptomatic instability reported by the patient and confirmed } \\
\text { by laxity on physical examination as defined by The Knee } \\
\text { Society Knee Score }\end{array}$ & 74.2 \\
\hline 8. Malalignment & & 88.4 & $\begin{array}{l}\text { Symptomatic malalignment reported by the patient and } \\
\text { confirmed radiographically with angular deformity in the } \\
\text { coronal plane }>10^{\circ} \text { from the mechanical axis }\end{array}$ & 82.1 \\
\hline 9. Stiffness [8] & 719.56 & 92.9 & $\begin{array}{l}\text { Limited ROM as reported by the patient and demonstrated in a } \\
\text { physical examination with extension limited to } 15^{\circ} \text { short of } \\
\text { full extension or flexion }<90^{\circ} \text { (not applicable if } \\
\left.\text { preoperative arc of motion }<75^{\circ}\right)\end{array}$ & 81.8 \\
\hline $\begin{array}{l}\text { 10. Deep periprosthetic } \\
\text { joint infection }\end{array}$ & 996.66 & 99.0 & $\begin{array}{l}\text { A deep periprosthetic joint infection can be diagnosed when } \\
\text { there is a sinus tract communicating with the prosthesis; or a } \\
\text { pathogen is isolated by culture from at least two separate } \\
\text { tissue or fluid samples obtained from the affected prosthetic } \\
\text { joint; or } 4 \text { of the following } 6 \text { criteria exist: elevated ESR and } \\
\text { serum CRP concentration; elevated synovial WBC count; } \\
\text { elevated synovial PMN; presence of purulence in the } \\
\text { affected joint; isolation of a microorganism in one culture of } \\
\text { periprosthetic tissue or fluid; or }>5 \text { neutrophils/high-power } \\
\text { field in } 5 \text { high-power fields observed from histologic } \\
\text { analysis of periprosthetic tissue at } \times 400 \text { magnification [22] }\end{array}$ & 88.9 \\
\hline $\begin{array}{l}\text { 11. Periprosthetic } \\
\text { fracture }\end{array}$ & 996.44 & 96.0 & $\begin{array}{l}\text { Periprosthetic fracture of the distal femur, proximal tibia, or } \\
\text { patella (operative or nonoperative treatment should be } \\
\text { recorded) }\end{array}$ & 93.9 \\
\hline $\begin{array}{l}\text { 12. Extensor mechanism } \\
\text { disruption }\end{array}$ & $\begin{array}{l}729.65 \\
727.66\end{array}$ & 95.9 & $\begin{array}{l}\text { Disruption of the extensor mechanism (surgical repair and/or } \\
\text { extensor lag should be recorded) }\end{array}$ & 94.9 \\
\hline $\begin{array}{l}\text { 13. Patellofemoral } \\
\text { dislocation }\end{array}$ & 996.42 & 95.9 & $\begin{array}{l}\text { Dislocation of the patella from the femoral trochlea (direction } \\
\text { of instability should be recorded) }\end{array}$ & 92.8 \\
\hline $\begin{array}{l}\text { 14. Tibiofemoral } \\
\text { dislocation }\end{array}$ & 996.42 & 94.9 & $\begin{array}{l}\text { Dislocation of the tibiofemoral joint (direction of instability } \\
\text { should be recorded) }\end{array}$ & 95.9 \\
\hline $\begin{array}{l}\text { 15. Bearing surface } \\
\text { wear }\end{array}$ & 996.46 & 95.8 & $\begin{array}{l}\text { Wear of the bearing surface symptomatic or requiring } \\
\text { reoperation }\end{array}$ & 81.3 \\
\hline 16. Osteolysis & 996.45 & 94.8 & $\begin{array}{l}\text { Expansile lytic lesion adjacent to one of the implants } \geq 1 \mathrm{~cm} \\
\text { in any one dimension or increasing in size on serial } \\
\text { radiographs/CT scans }\end{array}$ & 91.7 \\
\hline 17. Implant loosening & 996.41 & 99.0 & $\begin{array}{l}\text { Implant loosening confirmed intraoperatively or identified } \\
\text { radiographically as a change in implant position or a } \\
\text { progressive, radiolucent line at the bone-cement or } \\
\text { bone-implant interface }\end{array}$ & 91.7 \\
\hline
\end{tabular}


Table 1. continued

\begin{tabular}{|c|c|c|c|c|}
\hline $\begin{array}{l}\text { Complication/Adverse } \\
\text { event }\end{array}$ & $\begin{array}{l}\text { ICD-9 } \\
\text { code }\end{array}$ & $\begin{array}{l}\% \text { agree } \\
\text { with } \\
\text { complication }\end{array}$ & Definition & $\begin{array}{l}\% \text { agree } \\
\text { with } \\
\text { definition }\end{array}$ \\
\hline $\begin{array}{l}\text { 18. Implant fracture or } \\
\text { tibial insert dissociation }\end{array}$ & 996.43 & 97.9 & $\begin{array}{l}\text { Implant fracture or dissociation of the tibial insert from the } \\
\text { tibial implant }\end{array}$ & 91.6 \\
\hline 19. Reoperation & & 96.0 & $\begin{array}{l}\text { Return to the operating room related to the index TKA (reasons } \\
\text { for reoperation should be recorded) }\end{array}$ & 84.8 \\
\hline 20. Revision & & 97.9 & $\begin{array}{l}\text { Revision of one or more of the TKA implants (femur, tibia, } \\
\text { tibial insert, patella) }\end{array}$ & 92.6 \\
\hline 21. Readmission & & 84.8 & $\begin{array}{l}\text { Admission to the hospital for any reason during the first } \\
90 \text { days after TKA (reasons for admission and relation to } \\
\text { index TKA should be recorded) }\end{array}$ & 79.8 \\
\hline 22. Death & & 95.9 & $\begin{array}{l}\text { Death occurring for any reason during the first } 90 \text { days after } \\
\text { TKA (cause of death and relation to index TKA should be } \\
\text { recorded) }\end{array}$ & 89.8 \\
\hline
\end{tabular}

* All of the proposed TKA complications and adverse events and their definitions were endorsed by the members of The Knee Society $(\mathrm{p}<0.001)$; ESR = erythrocyte sedimentation rate; $\mathrm{CRP}=\mathrm{C}$-reactive protein; $\mathrm{WBC}=$ white blood cell; $\mathrm{PMN}=$ neutrophil percentage.

implants, Goldhahn et al. [9] suggested a standard protocol for reporting complications should be developed and endorsed by clinical investigators, professional organizations, and orthopaedic journals. The work of those authors stimulated this project by The Knee Society. We therefore developed a standardized list and standardized definitions for complications and adverse events associated with TKA.

Our workgroup report is subject to a several limitations. First, the list of TKA complications and adverse events was developed by a review of the literature and expert opinion, which is Level V evidence. Second, the orthopaedic literature does not have consensus definitions for many of the conditions proposed. Third, the list of complications was not validated by an analysis of a large database of patients with TKA. However, $100 \%$ of the clinical members of The Knee Society evaluated the proposed TKA complications, and The Knee Society endorsed the proposal. The Knee Society members who provided this collective expert opinion are generally considered experts and teachers regarding TKA, and thousands of TKA operations delivered over several decades provide the foundation for their opinions. Fourth, the TKA complications and adverse events presented in this report are not stratified based on severity. Stratification of these complications could improve reporting of TKA outcomes, and the TKA Complications Workgroup intends to address this topic in a future report. Fifth, standardization of complications would be clearer if they included the timing of complications. This will also be addressed in a future report.

Public reporting of outcomes for medical and surgical treatments is becoming more prevalent, and we expect public reporting and quality measurement will increase in the future. This list of TKA complications and adverse events may be helpful to stakeholders who create public reports regarding TKA. However, this list of TKA complications and adverse events must be used according to specific definitions and limitations for public reporting of complications. Reports must differentiate complications and adverse events because all adverse events are not complications. For example, when reporting the complication of deep periprosthetic joint infection for a hospital or a surgeon, the CDC defines surgical site infection as infection within 1 year of the index operation [2, 22]. Subsequent to 1 year, infection is an adverse event. Adverse event information is helpful to patients and surgeons who manage the long-term outcome of knee arthroplasty. However, adverse events should not be considered complications for public reporting.

Complications and adverse events are associated with all medical and surgical treatments. By identifying and defining 22 complications and adverse events associated with TKA, this project intended to improve quality and safety for TKA. This paper is intended to assist surgeons, researchers, health plans, and government officials in evaluating the surgical results and patient outcomes after knee arthroplasties. This project did not intend to identify problems that suggest a knee arthroplasty was not planned or performed correctly. This paper is not intended as a legal document, and the authors specifically reject the notion that these TKA complications and adverse events define substandard care. As noted earlier, and now emphasized, complications can be associated with medical treatments and surgical procedures despite the delivery of reasonable and safe care.

We suggest this standardized list of TKA complications and their standardized definitions, which were endorsed by The Knee Society, could improve reporting of TKA outcomes if they are endorsed and accepted by orthopaedic surgeons, orthopaedic professional societies, orthopaedic 
investigators, and orthopaedic journals. We further propose clinical trials and TKA outcome studies will be enhanced if this list of TKA complications and their definitions are utilized. Furthermore, standardization of reporting of TKA outcomes and complications could lead to improved patient selection, surgical procedures, clinical protocols, knee implants, and patient outcomes for TKA. Further study will be necessary to evaluate the validity of our suggestions.

Acknowledgments The authors thank John Garfi, MS, EMT, Lahey Clinic Medical Center, who assisted with the preparation of the manuscript, and Mario Moric, MS, Rush University Medical Center, who assisted with the statistical evaluation.

\section{References}

1. Bellamy N, Buchanan WW, Goldsmith CH, Campbell J, Stitt LW. Validation study of WOMAC: a health status instrument for measuring clinically important patient relevant outcomes to antirheumatic drug therapy in patients with osteoarthritis of the hip or knee. J Rheumatol. 1988;15:1833-1840.

2. Centers for Disease Control and Prevention. CDC/NHSN surveillance definition of healthcare-associated infection and criteria for specific types of infections in the acute care setting. January 1 , 2012. Available at: http://www.cdc.gov/nhsn/PDFs/pscManual/ 17pscNosInfDef_current.pdf. Accessed June 25, 2012.

3. Conaghan PG, Emerton M, Tennant A. Internal construct validity of the Oxford Knee Scale: evidence from Rasch measurement. Arthritis Rheum. 2007;57:1363-1367.

4. Dindo D, Demartines N, Clavien PA. Classification of surgical complications: a new proposal in a cohort of 6336 patients and results of a survey. Ann Surg. 2004;240:205-213.

5. Dixon MC, Brown RR, Parsch D, Scott RD. Modular fixedbearing total knee arthroplasty with retention of the posterior cruciate ligament. J Bone Joint Surg Am. 2005;87:598-603.

6. Dunbar MJ, Robertsson O, Ryd L, Lidgren L. Appropriate questionnaires for total knee arthroplasty: results of a survey of 3600 patients from the Swedish Knee Arthroplasty Registry. J Bone Joint Surg Br. 2001;83:339-344.

7. Fehring T, Odum S, Troyer J, Iorio R. Joint replacement access in 2016: a supply side crisis. J Arthroplasty. 2010;25:1175-1181.

8. Fitzsimmons SE, Vazquez EA, Bronson MJ. How to treat the stiff total knee arthroplasty? A systematic review. Clin Orthop Relat Res. 2010;468:1096-1106.

9. Goldhahn S, Sawaguchi T, Audige L, Mund R, Hanson B, Bhandari M, Goldhahn J. Complication reporting in orthopaedic trials: a systematic review of randomized controlled trials. J Bone Joint Surg Am. 2009;91:1847-1853.

10. Healy WL, Rana A, Iorio R. Hospital economics of primary total knee arthroplasty at a teaching hospital. Clin Orthop Relat Res. 2011;469:87-94.

11. Hensyl WR, ed. Stedman's Medical Dictionary. 25th ed. Baltimore, MD: Lippincott Williams \& Wilkins; 1990:336.
12. Insall JN, Dorr LD, Scott RD, Scott WN. Rationale of the Knee Society clinical rating system. Clin Orthop Relat Res. 1989;248:13-14.

13. Insall JN, Ranawat CS, Aglietti P, Shine J. A comparison of four models of total knee-replacement prostheses. J Bone Joint Surg Am. 1976;58:754-765.

14. Iorio R, Robb WJ, Healy WL, Berry DJ, Hozack WJ, Kyle RF, Lewallen DG, Trousdale RT, Jiranek WA, Stamos VP, Parsley BS. Orthopaedic surgeon workforce and volume assessment for total hip and knee replacement in the United States: preparing for an epidemic. J Bone Joint Surg Am. 2008;90:1598-1605.

15. Kelly MA, Clarke HD. Long-term results of posterior cruciatesubstituting total knee arthroplasty. Clin Orthop Relat Res. 2002; 404:51-57.

16. Knee Society. Bylaws. 2012. Available at: http://www.aahks.org/ about/AAHKSBylaws.pdf. Accessed April 4, 2012.

17. Kurtz S, Ong K, Lau E, Mowat F, Halpern M. Projections of primary and revision hip and knee arthroplasty in the United States from 2005 to 2030. J Bone Joint Surg Am. 2007;89:780-785.

18. Kurtz SM, Lau E, Ong K, Zhao K, Kelly M, Bozic KJ. Future young patient demand for primary and revision joint replacement: national projections from 2010 to 2030. Clin Orthop Relat Res. 2009;467:2606-2612.

19. Losina E, Walensky RP, Kessler CL, Emrani PS, Reichmann WM, Wright EA, Holt HL, Solomon DH, Yelin E, Paltiel AD, Katz JN. Cost-effectiveness of total knee arthroplasty in the United States: patient risk and hospital volume. Arch Intern Med. 2009;169:1102-1103, discussion 1121-1122.

20. McHorney CA, Haley SM, Ware JE Jr. Evaluation of the MOS SF-36 Physical Functioning Scale (PF-10): II. Comparison of relative precision using Likert and Rasch scoring methods. J Clin Epidemiol. 1997;50:451-461.

21. Noble PC, Scuderi GR, Brekke AC, Sikorskii A, Benjamin JB, Lonner JH, Chadha P, Daylamani DA, Scott WN, Bourne RB. Development of a new Knee Society Scoring System. Clin Orthop Relat Res. 2012;470:20-32.

22. Parvizi J, Zmistowiski BS, Berbari EF, Baver TW, Spinger BD, Della Valle CJ, Garvin KL, Mont MA, Wongworawat MD, Zalavras CG. New definition for periprosthetic joint infection (from the work group of the Musculoskeletal Infection Society). Clin Orthop Relat Res. 2011;469:2992-2994.

23. Ries MD, Philbin EF, Groff GD, Sheesley KA, Richman JA, Lynch F Jr. Improvement in cardiovascular fitness after total knee arthroplasty. J Bone Joint Surg Am. 1996;78:1696-1701.

24. Robertsson O, Dunbar MJ. Patient satisfaction compared with general health and disease-specific questionnaires in knee arthroplasty patients. J Arthroplasty. 2001;16:476-482.

25. Scuderi GR, Bourne RB, Noble PC, Benjamin JB, Lonner JH, Scott WN. The new Knee Society Knee Scoring System. Clin Orthop Relat Res. 2012;470:3-19.

26. Soohoo NF, Zingmond DS, Lieberman JR, Ko CY. Optimal timeframe for reporting short-term complication rates after total knee arthroplasty. J Arthroplasty. 2006;21:705-711.

27. Veen SJ, Steenbruggen J, Roukema J. Classifying surgical complications: a critical appraisal. Arch Surg. 2005;140:1078-1083.

28. Watkins-Castillo S. Orthopaedic Practice in the US 2004-2005. Rosemont, IL: American Academy of Orthopaedic Surgeons; 2004:1-4. 